\title{
An augmented cognitive behavioural therapy for treating post-stroke depression: description of a treatment protocol
}

\author{
Citation for published version (APA):
}

Kootker, J. A., Rasquin, S. M. C., Smits, P., Geurts, A. C., van Heugten, C. M., \& Fasotti, L. (2015). An augmented cognitive behavioural therapy for treating post-stroke depression: description of a treatment protocol. Clinical Rehabilitation, 29(9), 833-843. https://doi.org/10.1177/0269215514559987

\section{Document status and date: \\ Published: 01/09/2015}

DOI:

10.1177/0269215514559987

\section{Document Version:}

Publisher's PDF, also known as Version of record

\section{Document license:}

Taverne

Please check the document version of this publication:

- A submitted manuscript is the version of the article upon submission and before peer-review. There can be important differences between the submitted version and the official published version of record. People interested in the research are advised to contact the author for the final version of the publication, or visit the DOI to the publisher's website.

- The final author version and the galley proof are versions of the publication after peer review.

- The final published version features the final layout of the paper including the volume, issue and page numbers.

Link to publication

\footnotetext{
General rights rights.

- You may freely distribute the URL identifying the publication in the public portal. please follow below link for the End User Agreement:

www.umlib.nl/taverne-license

Take down policy

If you believe that this document breaches copyright please contact us at:

repository@maastrichtuniversity.nl

providing details and we will investigate your claim.
}

Copyright and moral rights for the publications made accessible in the public portal are retained by the authors and/or other copyright owners and it is a condition of accessing publications that users recognise and abide by the legal requirements associated with these

- Users may download and print one copy of any publication from the public portal for the purpose of private study or research.

- You may not further distribute the material or use it for any profit-making activity or commercial gain

If the publication is distributed under the terms of Article $25 \mathrm{fa}$ of the Dutch Copyright Act, indicated by the "Taverne" license above, 


\title{
An augmented cognitive behavioural therapy for treating post-stroke depression: description of a treatment protocol
}

Clinical Rehabilitation 2015, Vol. 29(9) 833-843 (C) The Author(s) 2014 Reprints and permissions: sagepub.co.uk/journalsPermissions.nav DOI: I0.1 I77/02692/55I4559987 cre.sagepub.com

๑SAGE

\section{Joyce A Kootker', Sascha MC Rasquin2,3, Peter Smits4, Alexander C Geurts', Caroline M van Heugten ${ }^{5,6}$ and Luciano Fasotti ${ }^{7,8}$}

This series of articles for rehabilitation in practice aims to cover a knowledge element of the rehabilitation medicine curriculum. Nevertheless they are intended to be of interest to a multidisciplinary audience. The competency addressed in this article is psychologist, occupational therapists, movement therapists and physicians working in rehabilitation medicine.

\begin{abstract}
Aim: Currently, no evidence-based treatment is available for mood problems after stroke. We present a new psychological intervention designed to reduce depressive complaints after stroke.

Method of protocol development: This intervention was based on cognitive behavioural therapy principles and was shown feasible in a pilot study. In order to meet the specific needs of stroke patients (concerning both sensori-motor, cognitive, and behavioural problems), we incorporated motivational interviewing, grief resolution, and psycho-education. We emphasised for each session to take into account the cognitive deficits of the patients (i.e. be concrete, accessible, structured, specific, and repeat information). Moreover, we augmented the psychologist-administered therapy with the contribution of an occupational or movement therapist aimed at facilitating patients' goal-setting and attainment. The intervention consisted of 12 onehour sessions with a psychologist and three or four one-hour sessions with an occupational or movement therapist. Currently, the effectiveness of the intervention is evaluated in a randomised controlled trial.

Discussion: The proposed psychological treatment protocol is innovative, as it applies cognitive behavioural therapy in a stroke-specific manner; moreover, it supports goal attainment by incorporating occupational or movement therapy sessions.
\end{abstract}

\section{Keywords}

Stroke, depression, anxiety, treatment protocol, cognitive behavioural therapy

Received: 22 May 2014; accepted: 26 October 2014

\footnotetext{
'Radboud Institute for Health Sciences, Radboud University Medical Centre, Nijmegen, The Netherlands

${ }^{2}$ Adelante Rehabilitation Foundation Limburg, Hoensbroek, The Netherlands

${ }^{3}$ CAPHRI, Maastricht University Medical Centre, Maastricht, The Netherlands

${ }^{4}$ Rehabilitation Centre, St. Maartenskliniek, Nijmegen, The Netherlands

${ }^{5}$ School for Mental Health and Neuroscience, Faculty of Health, Medicine and Life Sciences, Maastricht, The Netherlands
}

${ }^{6}$ Department of Neuropsychology and Psychopharmacology, Maastricht University, Maastricht, The Netherlands ${ }^{7}$ Donders Institute for Brain, Cognition and Behaviour, Radboud University Nijmegen, Nijmegen, The Netherlands ${ }^{8}$ Rehabilitation Medical Centre Groot Klimmendaal, Siza Support and Rehabilitation, Arnhem, The Netherlands

Corresponding author:

Joyce A Kootker, Radboud Institute for Health Sciences, Department of Rehabilitation, Radboud University Medical Centre, Nijmegen, PO Box 9101, 6500 HB, The Netherlands. Email: joyce.kootker@radboudumc.nl 


\section{Introduction}

Following a stroke, approximately $70 \%$ of survivors experience considerable long-term sensorimotor, cognitive, and/or behavioural impairments. These impairments often limit normal daily life activities and may restrict social participation, ${ }^{1-3}$ which may lead to feelings of depression. Although the reported prevalence of mood complaints varies, approximately more than $30 \%$ of all stroke survivors experience severe emotional complaints ${ }^{4-6}$ that negatively impact their quality of life. ${ }^{7,8}$

Developing treatment programmes for depressive symptoms in patients after stroke requires a basic understanding of the underlying aetiology. This aetiology has been the subject of considerable debate. Researchers that investigated neuroanatomical and neurochemical substrates of poststroke depression have not been able to establish that post-stroke depression can be attributed to a particular type of stroke or level of stroke severity. ${ }^{9-11}$ Moreover, it has been suggested that the relationship between functional impairments and post-stroke depression is mediated by the significance that the patient attributes to his/her impairments. ${ }^{12,13}$ From this perspective, post-stroke depression may be viewed as the result of an inadequate adjustment to the consequences of stroke. Therefore, it is important to address the reactive aspects of post-stroke depression when developing a psychological intervention for depressive complaints after stroke. Additionally, since post-stroke depression often coincides with increased anxiety, ${ }^{4,14,15}$ feelings of anxiety should also be taken into account in such an intervention.

Mood disturbances after stroke are commonly treated with pharmacological agents. However, the benefits of pharmacotherapy in the treatment of post-stroke depression are debatable. ${ }^{16}$ Psychological interventions are used less frequently, possibly because their effects are also unclear. ${ }^{17-19}$ Yet, such interventions have yielded beneficial effects on mood disturbances in patients with other chronic disorders, such as cancer and diabetes. $^{20,21}$ Within the broad field of psychotherapy, cognitive behavioural therapy seems one of the most promising methods to address post-stroke depression. In this respect, it is important to note that cognitive behavioural therapy was recently found to be beneficial for treating post-stroke fatigue. ${ }^{22}$ The core assumption in cognitive behavioural therapy is that thoughts - rather than external factors such as people, situations, or events - drive feelings and behaviours. If one can change the way patients think, this can improve their feelings and actions, even if the situation does not change. A key advantage of cognitive behavioural therapy over pharmacotherapy is that it is more effective at preventing the relapse of emotional symptoms, as it causes structural changes in irrational cognitions and negative thoughts. ${ }^{23}$ Another advantage is that cognitive behavioural therapy has a more favourable side-effect profile than pharmacotherapy. ${ }^{16}$

The goal of the current article is to present a new psychological treatment protocol for poststroke depression based on cognitive behavioural therapy, which is currently evaluated in a multicentre randomised controlled trial as part of the Restore4Stroke study in the Netherlands ${ }^{24}$ (Dutch Trial Register NTR2999). We will first describe the theoretical background of the treatment protocol, followed by the content of the intervention, and a comprehensive discussion. Two case descriptions are presented in boxes to illustrate how the protocol can be applied in clinical practice.

\section{Theoretical background}

The psychological treatment of post-stroke depression is still in its infancy. The application of conventional cognitive behavioural therapy for post-stroke depression has not yielded unambiguous results yet. To date, only one randomised controlled trial examined the effect of cognitive behavioural therapy on post-stroke depression. In this trial, Lincoln and Flannaghan ${ }^{25}$ found no group differences of cognitive behaviour therapy vs. interviews. The authors acknowledged that their study had several methodological shortcomings, such as early inclusion after stroke ( $<1$ month), low therapy intensity, and the use of a relatively inexperienced therapist who participated in both interventions, thereby running the risk of 'contamination'. ${ }^{25}$ Most importantly, the cognitive behavioural therapy did not take into account individual cognitive and/or sensorimotor deficits, nor were the participants 
provided with practical advice about how to achieve behavioural change.

Many stroke patients have sensory, motor, and/ or cognitive impairments that limit their behavioural potential. Therefore, challenging and modifying irrational and negative thoughts using traditional cognitive behavioural therapy does not necessarily lead to effective behavioural changes. Cognitive impairments may lead to problems with information processing and, for instance, the correct understanding of the content of interventions. Stroke patients also may lack processing speed and can experience memory problems, which complicates the course of therapy. In addition, after having experienced a traumatic event (i.e. stroke), patients regularly misinterpret their bodily sensations, inducing fear and anxiety, which may hamper the process of behaviour change. Also, grief that accompanies a traumatic event makes the patient less receptive to cognitive behavioural therapy.

In an attempt to take into account these impairments, and to enhance the applicability of cognitive behavioural therapy in the treatment of post-stroke depression, Broomfield et al. ${ }^{23}$ recommended the integration of the following five psychological approaches that will be illustrated in the procedure section.

- Motivational interviewing. ${ }^{26,27}$

- Grief resolution. ${ }^{28}$

- Cognitive deficits adaptation. ${ }^{29}$

- Selective optimisation with compensation. 23,30,31

- Executive skills training. ${ }^{23}$

\section{Method of protocol development}

We previously conducted a pilot study to assess the feasibility of cognitive behavioural therapy in five patients. An existing cognitive behavioural therapy intervention developed for patients with chronic disease ${ }^{32}$ was modified to fit the cognitive impairments of stroke patients. ${ }^{33}$ We reduced the amount of information and repeated information several times throughout the intervention. The intervention reduced mood complaints in three out of five patients. Next to that, we showed that the intervention was feasible. After evaluation of this pilot study, we further developed the protocol by incorporating the recent suggestions of Broomfield and colleagues as follows. ${ }^{23}$

1. Throughout the treatment, the psychologist used motivational interviewing to enhance the patient's motivation for behavioural change. ${ }^{26,27}$ By asking open-ended questions, discussing pros and cons of behaviour change, and by addressing goal planning to bring about behavioural change, the patient was encouraged to be creative and think autonomously for setting therapy goals and find ways to improve his/her self-efficacy (see Box 1).

2. Early in the treatment protocol, the psychologist promoted grief resolution by explaining the phases of bereavement and by discussing the effects of reduced physical independence, mobility, cognitive capacity, and emotional control on self-esteem and future perspective (see Box 1 ).

3. Throughout the treatment, cognitive impairments were taken into account when explaining and implementing the principles of cognitive behavioural therapy. ${ }^{34}$ In line with 'cognitive deficits adaptation', the psychologist used cognition schemes to explain the relationship between thoughts, feelings, and actions in a step-by-step fashion (see Figure 1). In addition, the intensity of therapy sessions was adjusted to the patient's cognitive capacities, while psychologists were instructed to adjust their communication style to the patient's functional level through the consistent use concrete, repetitive, accessible, structured, and specific (CRASS) communication principles. ${ }^{35}$ For example, therapists communicated the essentials of therapy by talking slowly, illustrating them with tangible examples, while avoiding professional jargon. During each session, the psychologist repeatedly mentioned the most important components, thereby ensuring that the patient fully understood all key elements. 'Take home' information sheets also described the most important therapy components. 
4. The most crucial adjustment of our treatment protocol was based on 'selective optimisation with compensation'. Based on this approach, the psychologist-administered cognitive behavioural therapy was augmented with three sessions of occupational or movement therapy to facilitate goal-setting and attainment. An occupational or movement therapist supported patients with functional limitations (or doubts about their capacities) by first identifying meaningful personal goals and then helping them to achieve these goals.

5. When a patient reported feelings of anxiety in addition to depressive complaints, cognitive behavioural therapy also addressed anxietyrelated thoughts and problems. Moreover, a fourth occupational or movement therapy session was planned to teach the patient relaxation techniques (e.g. breathing exercises), as advised by the Dutch Heart Foundation. ${ }^{36}$ The aim of this extra session was to alleviate anxiety-driven bodily tension that might impede the patient's ability to reach his/her activityrelated goals.

Box I: Motivational interviewing and grief resolution.

Patient MC used to be a consultant in organisation management. After his stroke, he experienced considerable difficulty resuming his professional work, causing loss of self-esteem and sense of identity. When discussing therapy goals, at first, $\mathrm{MC}$ aimed to regain his old job. By posing an open-ended question about the way he thought he would attain this goal, $\mathrm{MC}$ gradually realised that regaining his former job was out of reach. Moreover, by making a pro-con list, he realised that sticking to the current situation would cost too much energy and lead to many mistakes. Before encouraging him to think about other types of occupation, the psychologist stimulated $\mathrm{MC}$ to reflect on and discuss the grief and emotional impact of his vocational loss.

\section{Procedure}

Table 1 gives an overview of the content of the treatment protocol.
Target group. This treatment protocol was designed for the Restore4Stroke randomised controlled trial aimed at patients with chronic mood complaints after stroke; until now, the protocol has been applied in this trial only. ${ }^{24}$ Stroke patients with a pretreatment score of $>7$ on the depression subscale of the Hospital Anxiety and Depression Scale were eligible for participation (see Table 1). Although the Hospital Anxiety and Depression Scale anxiety subscore was not regarded for inclusion, it was used to individualise the treatment, for instance to indicate the need of additional relaxation exercises. The following exclusion criteria were applied: insufficient communication skills, a diagnosis of a 'major depression' that required pharmacotherapy (based on the medical file), and a history of prestroke mood disorder or any comorbidity that could affect mood. ${ }^{12}$

Role of therapists. The treatment protocol was administered by a certified, experienced healthcare psychologist who was familiar with treating depression and providing rehabilitation to patients with stroke. Prior to working with the protocol, each psychologist received two hours of training by an expert psychologist with ample experience in cognitive behavioural therapy. If needed, the expert psychologist was available for assistance throughout the intervention. To prepare the goal-setting stage, the psychologist selected either an occupational or movement therapist, depending on the patient's tentative goals: an occupational therapist was preferred when the goals included optimising activities in the domains of self-care, leisure, household, and/or work; a movement therapist was chosen when the goals included improving mobility-related activities, such as sports and walking. Because of their education and experience, occupational and movement therapists are optimally equipped to assess patients' individual functional limitations and identify potential compensatory strategies. They worked in parallel with the psychologist to successfully translate the patients' goals into daily life and help them achieve behavioural change. By maintaining close contact with the individual patient and the treating psychologist, it was ensured that all parties adhered to the same 


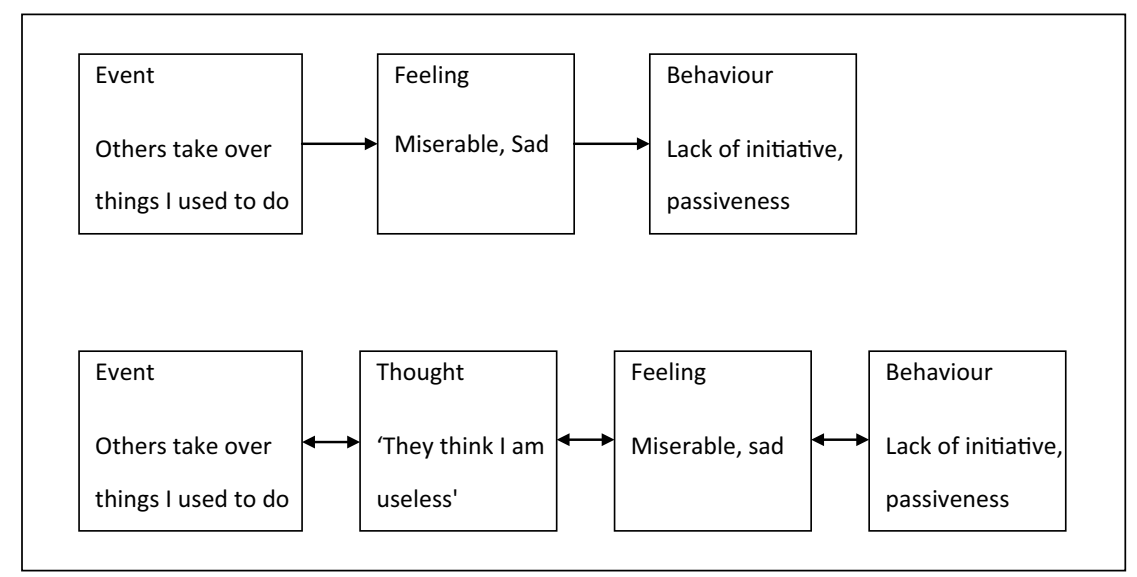

Figure I. Hidden cognition scheme as it is introduced in the expanded four-step scheme (bottom row). The top row shows the simplified three-step scheme.

Table I. Characteristics of the protocol: Augmented Cognitive Behavioural Therapy.

Inclusion criteria

Exclusion criteria

Therapists' competence

Location

Number of sessions

Duration of session

Materials

Tailoring
Patients with post-stroke depression with or without anxiety as defined by a depression sub-score on the HADS $>7$. Any type of stroke in the past. Depressed mood occurring $>6$ months post-stroke. Sufficient communication skills.

Patients with prestroke physical disability (Barthel Index: <19/20). Inpatients. Co-morbidity that could affect mood. Diagnosis of 'major depression' requiring medication. Diagnosis of prestroke depression or previous psychiatric care for depression.

Psychologist: Healthcare psychologist with CBT experience and familiarity with stroke rehabilitation.

Occupational or movement therapist: Familiarity with stroke rehabilitation. Both therapists: Received training by developer of protocol for correct application.

Psychologist sessions: In the psychologist's office.

Occupational or movement therapist sessions: In the rehabilitation facility, at various locations within the community, or at the patient's home.

15-16 individual sessions over a period of four months; II sessions with the psychologist and one session with both the psychologist and the occupational or movement therapist; 3-4 additional sessions with the occupational or movement therapist alone.

One hour per week, with each session comprised of two blocks of 20-25 minutes separated by a 10-15 minute break.

Protocol booklet for therapist; ACS cards for photo interview; homework assignment booklet for patient.

The psychologist has certain degrees of freedom concerning content of the final sessions, either attention to problems with acquired skills or evaluation of the intervention, depending on the patient's progress.

ACS: Activity Card Sorting; CBT: cognitive behavioural therapy; HADS: Hospital Anxiety and Depression Scale. 
treatment principles, while the psychologist kept the lead in the intervention.

In the case of increased anxiety (i.e. Hospital Anxiety and Depression Scale anxiety subscore $>7$ ), the patient received a fourth session with the therapist that was entirely devoted to teaching relaxation techniques.

Treatment stages. The treatment protocol consisted of 15-16 individual treatment sessions. Twelve sessions were administered by the psychologist, and three (or four) additional sessions by the occupational or movement therapist. The treatment protocol consisted of five successive stages (see Table 2).

1. In Stage 1 (three sessions), the psychologist began building rapport with the patient and creating a safe atmosphere by striving to experience the world from the patient's perspective without judgement or criticism. This was followed by grief resolution, which entailed reassurance of the patient with regard to emotional reactions to the consequences of his/her stroke by explaining that such reactions are normal after a painful and threatening life event (see Box 1). After that, psycho-education encompassed the provision of information about the consequences of stroke and useful compensatory strategies. In addition, the psychologist emphasised the relationship between becoming more active in daily life and the positive impact on emotions and behaviour.

2. Stage 2 (two sessions) was the goal-setting stage. The first of the two sessions was administered by the psychologist; the second was multidisciplinary and delivered together with the occupational or movement therapist. In line with CRASS principles, the protocol was made 'accessible' to the patient using the Activity Card Sorting. This tool facilitated the discussion about the patient's personal activities and attainable goals. ${ }^{37}$ The Activity Card Sorting consists of 78 pictures representing people engaged in a wide array of activities, including leisure, sports, and daily life activities. Thus, the stroke patient was given concrete examples to help him/her select personal goals. In preparation for the goal-setting sessions, patients listed the Activity Card Sorting cards most relevant to them as homework assignment to become familiar with the themes of the cards.

- In the first goal-setting session prestroke activity levels were discussed, using the Activity Card Sorting cards that the patient had selected. The psychologist and patient then discussed the patient's current activity levels. Finally, activities that could help achieve the patient's desired future situation were addressed, resulting in five tentative therapy goals. The content of these goals determined whether the psychologist contacted either the occupational or movement therapist. The psychologist introduced the patient to the therapist and together they prepared the multidisciplinary session.

- During the second session, each goal was discussed with respect to its feasibility. The psychologist and therapist, together with the patient, designed a concrete and realistic plan. This plan encompassed three specific agreed-upon therapy goals, taking into account the patient's cognitive and physical limitations. This plan detailed the contents and timing of the three additional sessions in the following two stages with the occupational or movement therapist.

3. In Stage 3 (two sessions), the psychologist used cognitive behavioural therapy to help the patient recognise the thoughts that triggered negative mood and behaviour (see Box 2). In these sessions, the psychologist used schemes to explain negative and positive cognitions and to prepare the homework assignments (see Figure 1).

- First, the psychologist explained a 'threestep sequence' of occurrences: events leading to feelings leading to behaviour (event $\rightarrow$ feeling $\rightarrow$ behaviour). The patient was taught that events engender feelings, which in turn influence behaviour. The patient was then encouraged to think of specific events in his/her daily life that led to negative feelings and subsequent behaviour. When he/she 
Table 2. Structure of the protocol (psychologists' sessions).

Stage Topic Session Therapeutic content $\begin{aligned} & \text { How: Therapeutic Homework } \\ & \text { techniques }\end{aligned}$

I. Purpose: Helping patients recognise their problems and provide information about post-stroke depression

I Acquaintance I Building rapport Introduction, getting and psycho-

education

2

3

Recognising bereavement and loss

Psycho-education to know the patient

and creating a safe atmosphere for problem

disclosure

Grief discussion, checking homework compliance Motivational interviewing techniques to help patients explore what they want to achieve

\section{Purpose: Goal-setting}

2

$\begin{array}{lll}\text { Goal-setting } & 4 & \text { Goal-setting using ACS } \\ & 5 & \begin{array}{l}\text { Goal selection: } \\ \text { Interdisciplinary } \\ \text { session with } \\ \text { occupational or } \\ \text { movement therapist } \\ \text { and psychologist }\end{array}\end{array}$

3. Purpose: Exploring irrational cognitions and false beliefs

3

Cognitive 6
therapy

7

Reflect on 'hidden cognition': Rational or

Introduction CBT:

Recognising 'hidden cognition' irrational?

4. Purpose: Challenging and altering cognitions and false beliefs

Challenging $8 \quad \begin{aligned} & \text { Challenging irrational } \\ & \text { thoughts }\end{aligned}$
'negative
cognitions'

Check if patients understand three-step sequence; fill out one or two schemes with the patient to take home

Discuss three-step sequences from homework assignments and introduce the hidden cognition/thought

Use motivational interviewing to support patients in challenging negative thoughts
$R$ : Information leaflet

A: Problem description

R \& A: See Session I

R: Relationship behaviour and mood

A: Diary of activities and concurrent mood; writing down which ACS pictures are, or have once been relevant

R: Goal-setting A: Evaluating tentative goals

A: Evaluating and reading concrete plan for therapy goals

R: Relationship thoughts and mood

A: From three-step to four-step cognition schemas

$R$ : Influence of thought on mood

A: Four-step sequences: rational or irrational?

R: Reconsidering thought patterns

A: Changing irrational thoughts into helping thoughts 
Table 2. (Continued)

\begin{tabular}{|c|c|c|c|c|c|}
\hline Stage & Topic & Session & Therapeutic content & $\begin{array}{l}\text { How: Therapeutic } \\
\text { techniques }\end{array}$ & Homework \\
\hline & & 9 & Changing cognitions & $\begin{array}{l}\text { Support patients in } \\
\text { replacing negative } \\
\text { thoughts }\end{array}$ & R \& A: See Session 8 \\
\hline & & 10 & $\begin{array}{l}\text { Changing cognitions } \\
\text { consolidation }\end{array}$ & $\begin{array}{l}\text { Therapists either assist } \\
\text { in challenging thoughts } \\
\text { or use this session for } \\
\text { evaluation }\end{array}$ & $\begin{array}{l}\text { R: Rephrasing irrational } \\
\text { beliefs } \\
\text { A: Evaluation of Session } \\
8 \text { and } 9\end{array}$ \\
\hline \multicolumn{6}{|c|}{ 5. Purpose: Relapse prevention } \\
\hline \multirow[t]{3}{*}{5} & $\begin{array}{l}\text { Relapse } \\
\text { prevention }\end{array}$ & II & $\begin{array}{l}\text { Signals of relapse and } \\
\text { future strategies }\end{array}$ & $\begin{array}{l}\text { Let patients evaluate their } \\
\text { attained skills and goals. } \\
\text { Support is given on topics } \\
\text { patients want to improve }\end{array}$ & $\begin{array}{l}\text { R: Keeping up the good } \\
\text { work } \\
\text { A: Signals for negative } \\
\text { mood and future goals }\end{array}$ \\
\hline & & 12 & $\begin{array}{l}\text { Evaluation and } \\
\text { termination }\end{array}$ & $\begin{array}{l}\text { Prepare patients for } \\
\text { future situations. Create }\end{array}$ & R: Evaluation of goal \\
\hline & & & & $\begin{array}{l}\text { a take-home relapse } \\
\text { plan. Create four-step } \\
\text { sequences for anticipated } \\
\text { future situations }\end{array}$ & $\begin{array}{l}\text { A: Set future goals, } \\
\text { evaluate own progress }\end{array}$ \\
\hline
\end{tabular}

A: assignment; ACS: Activity Card Sort; CBT: cognitive behavioural therapy; R: reading.

understood this sequence of occurrences, a fourth step ('hidden cognition') was added to the explanatory scheme (event $\rightarrow$ thought $\rightarrow$ feeling $\rightarrow$ behaviour). ${ }^{34}$

- Hidden cognitions are thoughts that are not directly accessible, but can be made explicit by paying specific attention to the sequence of occurrences. During the homework assignments, the patient was advised to fill in the new 'four-step sequence': event $\rightarrow$ thought $\rightarrow$ feeling $\rightarrow$ behaviour (Figure 1). Once the patient was familiar with this technique, the psychologist explained that hidden cognitions may either have a negative or a positive influence on feelings and behaviour (see Box 2). ${ }^{34}$

4. In Stage 4 (three sessions), the patient was taught to challenge specific irrational, negative thoughts and to change these thoughts into rational 'helping' thoughts. The patient and psychologist together analysed concrete examples of four-step sequences, thereby teaching the patient to use these examples in homework assignments. Primarily, the patient's three therapy goals were used as a basis to apply the four-step sequences. During the homework assignments, the patient practised reappraising events based on helping and rational thoughts (see Box 2). In this stage, the psychologist repeatedly tested whether the patient fully understood the four-step sequences and was constantly in close contact with the occupational or movement therapist to followup on goal attainment in terms of achieving actual behavioural change.

5. In Stage 5 (two sessions), the treatment protocol was devoted to identifying relapse symptoms and evaluation. During the penultimate session, the psychologist discussed a possible future relapse of 'old' feelings and behaviours, which entailed listing the feelings that were once problematic. Subsequently, the patient was encouraged to manage recurrences of these feelings by applying the same cognitive behavioural techniques that were previously taught. Accordingly, he/she prepared a four-step scheme that could be used in future situations. The patient was stimulated to continue using a homework booklet after 
the therapy had ended. The last session was used for evaluation by asking the patient's opinion about the treatment process.

Box 2: Recognising and adjusting irrational thoughts.

Patient RS suffered from a stroke one year earlier. He avoided visiting his football club since he had been involved in an 'embarrassing situation' in which he had called a friend by the wrong name. As the psychologist discussed this situation (wrong name for a friend) - his accompanying feelings (shame) - and ensuing behaviour (avoid going to social events), 'hidden thoughts' were explored by posing questions such as: 'What did you think at this particular moment?; Do people generally get labelled after misnaming a person?'. The patient described a hidden thought as 'off course the other person thinks I am an idiot'. Then, the irrational aspects of this particular thought were further explored by questions such as: 'Does this thought actually reflect reality?; Can you imagine a more realistic thought to deal with this situation?'. Accordingly, RS asked his friend what he thought of him. These experience made him believe that people did not actually consider him stupid. Moreover, RS now explains to people in advance that he sometimes tends to forget names or relevant information. Next to that, he often points out that it would be of help when people would signal his mistakes.

\section{Discussion}

Given the urgent need for an effective therapy, ${ }^{23,33}$ we developed an augmented cognitive behavioural therapy protocol for treating depressive symptoms after stroke. Because depression in the chronic post-stroke phase is assumed to be mainly reactive in nature, cognitive behavioural therapy may be the most promising treatment. The augmentation which was a multidisciplinary approach using cotherapy by both a psychologist and an occupational or movement therapist - was expected to facilitate realistic goal-setting and effective goal attainment, by taking into account the individual patient's preferences, as well as his/her physical and cognitive capacities. The aim of the intervention was to give patients with depressive symptoms (and possible concurrent feelings of anxiety) the cognitive tools to realise behavioural change, thereby improve their self-efficacy. At the same time, patients were taught to manage the functional consequences of their stroke more effectively. To reach this goal, we incorporated several suggestions from previous studies, ${ }^{23,24,33}$ and we adapted the cognitive behavioural therapy protocol by incorporating motivational interviewing, ${ }^{26,27}$ adding sessions devoted to grief resolution, ${ }^{28}$ and addressing cognitive impairments using psycho-education ${ }^{29}$ and CRASS communication principles. ${ }^{35}$ Wherever possible, the functional consequences of stroke were optimised or compensated. ${ }^{23,30,31}$

The treatment protocol presented here has several strengths and limitations. The major strength is that the proposed intervention is innovative, as it applies cognitive behavioural therapy in a strokeadjusted manner, a feature not found in former applications of cognitive behavioural therapy for post-stroke depression. The intervention is also innovative because it supports goal attainment by incorporating occupational or movement therapy sessions. Another strength is that we included the treatment of concurrent anxiety complaints. Anxiety and depressive symptoms often co-occur following stroke. Moreover, feelings of anxiety can hinder the patients' actual performance of activities. Therefore, we addressed feelings of anxiety in our treatment protocol when applicable. Although we incorporated only a brief intervention for anxiety, we recognise that our treatment protocol may not be suitable for patients with severe anxiety disorders that require other therapeutic approaches, such as systematic desensitisation and graded exposure. ${ }^{34}$

As for limitations, we acknowledge that a multifaceted treatment protocol is hard to test for its specific efficacy, because the various elements incorporated may differently contribute to mood improvement in different individuals. Indeed, research in the field of psychological interventions for post-stroke depression is in a 'proof-ofprinciple' stage, in which effective treatments or combinations of treatments are still sought after. More fine-grained analyses of effective or ineffective treatment elements should therefore be 
subject of future studies. Although we incorporated nearly all of the suggestions made by Broomfield et al., ${ }^{23}$ we opted not to include executive skills training in our treatment protocol. Broomfield and colleagues reported that patients with severe executive problems are usually excluded from intervention trials for post-stroke depression, and argued that combining executive skills training with cognitive behavioural therapy may help such patients to better engage in therapy. ${ }^{23}$ We do agree that such a combined treatment approach might be of value for some patients, however, we did not incorporate distinct executive skills training as a standard component, because such a treatment is relatively long and complex, which would unduly prolong the treatment in many patients without executive problems.

\section{Clinical message}

- Psychological interventions for poststroke depression should be adjusted to the sensori-motor, cognitive, and behavioural impairments observed in many stroke survivors.

- Cognitive behavioural therapy is a promising method for treating poststroke depressive symptoms and can take into account concurrent feelings of anxiety.

- Cognitive behavioural therapy for poststroke depression can effectively be augmented with occupational or movement therapy to support individual patients in goal-setting and goal attainment, taking into account their physical and cognitive abilities.

\section{Conflict of interest}

The authors declare that there is no conflict of interest.

\section{Funding}

This research received no specific grant from any funding agency in the public, commercial, or not-for-profit sectors.

\section{References}

1. Bour A, Rasquin S, Aben I, Boreas A, Limburg M and Verhey F. A one-year follow-up study into the course of depression after stroke. J Nutr Health Aging 2010; 14(6): 488-493.

2. Ekstam L, Uppgard B, Kottorp A and Tham K. Relationship between awareness of disability and occupational performance during the first year after a stroke. $\mathrm{Am}$ J Occupat Ther 2007; 61(5): 503-511.

3. Hartman-Maeir A, Eliad Y, Kizoni R, Nahaloni I, Kelberman $\mathrm{H}$ and Katz N. Evaluation of a long-term community based rehabilitation program for adult stroke survivors. NeuroRehabil 2007; 22(4): 295-301.

4. Lincoln NB, Brinkmann N, Cunningham S, et al. Anxiety and depression after stroke: a 5 year follow-up. Disabil Rehabil 2013; 35(2): 140-145.

5. Ayerbe L, Ayis S, Wolfe CD and Rudd AG. Natural history, predictors and outcomes of depression after stroke: systematic review and meta-analysis. $\mathrm{Br} J$ Psychiatry 2013; 202(1): 14-21.

6. Ayerbe L, Ayis SA, Crichton S, Wolfe CD and Rudd AG. Natural history, predictors and associated outcomes of anxiety up to 10 years after stroke: the South London Stroke Register. Age Ageing 2014; 43(4): 542-547.

7. Nys GMS, van Zandvoort MJE, van der Worp HB, et al. Early cognitive impairment predicts long-term depressive symptoms and quality of life after stroke. J Neurol Sci 2006; 247(2): 149-156.

8. Ayerbe L, Ayis S, Crichton S, Wolfe CD and Rudd AG. The long-term outcomes of depression up to 10 years after stroke; the South London Stroke Register. $J$ Neurol Neurosurg Psychiatry 2014; 85(5): 514-21. DOI: 10.1136/jnnp-2013-306448.

9. Carson AJ, MacHale S, Allen K, et al. Depression after stroke and lesion location: a systematic review. Lancet 2000; 356(9224): 122-126.

10. Shimoda K and Robinson RG. The relationship between poststroke depression and lesion location in long-term follow-up. Biol Psychiatry 1999; 45(2): 187-192.

11. Gainotti G, Azzoni A and Marra C. Frequency, phenomenology and anatomical-clinical correlates of major poststroke depression. Br J Psychiatry 1999; 175: 163-167.

12. Sato R, Bryan RN and Fried LP. Neuroanatomic and functional correlates of depressed mood: the Cardiovascular Health Study. Am J Epidemiol 1999; 150(9): 919-929.

13. Gainotti G. The neuropsychological assessment and treatment of emotional disorders. In: Halligan P and Kischka UMJ (eds) Oxford handbook of clinical neuropsychology. Oxford: Oxford University Press, 2001.

14. Broomfield NM, Scoular A, Welsh P, Walters M and Evans JJ. Poststroke anxiety is prevalent at the population level, especially among socially deprived and younger age community stroke survivors. Int J Stroke 2013. Epub ahead of print. DOI: 10.1111/ijs.12109.

15. Thomas SA, Walker MF, Macniven JA, Haworth H and Lincoln NB. Communication and Low Mood (CALM): 
A randomized controlled trial of behavioural therapy for stroke patients with aphasia. Clin Rehabil 2013; 27(5): 398-408.

16. Hackett ML, Anderson CS and House AO. Management of depression after stroke: a systematic review of pharmacological therapies. Stroke 2005; 36(5): 1098-1103.

17. Hackett ML, Anderson CS, House AO and Xia J. Interventions for treating depression after stroke. Cochrane Database Syst Rev 2008; (4): CD003437. DOI: 10.1002/14651858.CD003437.pub3. Review

18. Anson K and Ponsford J. Evaluation of a coping skills group following traumatic brain injury. Brain Inj 2006; 20(2): 167-178.

19. Bedard M, Felteau M, Mazmanian D, et al. Pilot evaluation of a mindfulness-based intervention to improve quality of life among individuals who sustained traumatic brain injuries. Disabil Rehabil 2003; 25(13): 722-731.

20. Cuijpers P. Prevention of depression in chronic medical disorders: A pilot study. Psychol Reports 1988: 735-738.

21. Cuijpers P, Smit F, Bohlmeijer E, Hollon SD and Andersson G. Efficacy of cognitive-behavioural therapy and other psychological treatments for adult depression: meta-analytic study of publication bias. $\mathrm{Br} J$ Psychiatry 2010; 196(3): 173-178.

22. Zedlitz AM, Rietveld TC, Geurts AC and Fasotti L. Cognitive and graded activity training can alleviate persistent fatigue after stroke: a randomized, controlled trial. Stroke 2012; 43(4): 1046-1051.

23. Broomfield NM, Laidlaw K, Hickabottom E, et al. Poststroke depression: the case for augmented, individually tailored cognitive behavioural therapy. Clin Psychol Psychother 2011; 18(3): 202-17. DOI: 10.1002/cpp.711.

24. Kootker JA, Fasotti L, Rasquin SM, van Heugten CM and Gurts A. The effectiveness of an augmented cognitive behavioural intervention for post-stroke depression with or without anxiety (PSDA): the Restore4Stroke-PSDA trial. BMC Neurol 2012; 12: 51.

25. Lincoln NB and Flannaghan T. Cognitive behavioral psychotherapy for depression following stroke: a randomized controlled trial. Stroke 2003; 34(1): 111-115.
26. Arkowitz $\mathrm{H}$ and Westra HA. Introduction to the special series on motivational interviewing and psychotherapy. $J$ Clin Psychol 2009; 65(11): 1149-1155.

27. Burke BL, Arkowitz $\mathrm{H}$ and Menchola M. The efficacy of motivational interviewing: a meta-analysis of controlled clinical trials. J Consult Clin Psychol 2003; 71(5): 843-861.

28. Torges CM, Stewart AJ and Nolen-Hoeksema S. Regret resolution, aging, and adapting to loss. Psychol Aging 2008; 23(1): 169-180.

29. Hibbard MR, Grober SE, Gordon WA, Aletta EG and Freeman A. cognitive therapy and the treatment of poststroke depression. Top Geriatric Rehabil 1990; 5(3): 43-55.

30. Freund AM and Baltes PB. Selection, optimization, and compensation as strategies of life management: correlations with subjective indicators of successful aging. Psychol Aging 1998; 13(4): 531-543.

31. Baltes PB. On the incomplete architecture of human ontogeny. Selection, optimization, and compensation as foundation of developmental theory. Am Psychol 1997; 52(4): 366-380.

32. Cuijpers P. Prevention of depression in chronic general medical disorders: A pilot study. Psychol Reports 1998; 82(3, Pt 1): 735-738.

33. Rasquin SM, Van De SP, Praamstra AJ and van Heugten CM. Cognitive-behavioural intervention for depression after stroke: five single case studies on effects and feasibility. Neuropsychol Rehabil 2009; 19(2): 208-222.

34. McMullin RE. The new handbook of cognitive therapy techniques. New York: Norton, 1986.

35. Judd T. Neuropsychotherapy and community integration; Brain illness, emotions and behaviour. New York: Kluwer Academic/Plenum Publishers, 1999.

36. van Erp J. Relaxation exercises (ontspanningsoefeningen; bodyscan, aandacht voor uw lichaam). De hart\&vaatgroep, 2010.

37. Eriksson G, Chung J, Beng L, et al. Occupations of older adults: a cross cultural description. OTJR 2011; 31(4): 182-192. 